\title{
Correlação Clínico-Radiográfica \\ Caso 10/2004 - Instituto do Coração do Hospital das Clínicas da FMUSP
}

\author{
Edmar Atik \\ São Paulo, SP
}

Dados clínicos - Em lactente com 41 dias do sexo masculino e de cor branca, cianose ao choro era notada desde o nascimento, mas sem cansaço, tendo apresentado neste período bom ganho ponderal. Ao exame físico estava com taquipnéia discreta, acianótico e com pulsos normais. A pressão arterial era de $85 / 68$ $\mathrm{mmHg}$, a freqüência cardíaca de 160 bpm e o peso de 4.295 g. A aorta não foi palpada na fúrcula. No precórdio havia impulsões discretas na borda esternal esquerda e o ictus cordis não foi palpado. A $2^{\text {a }}$ bulha era hipofonética na área pulmonar e a $1^{\text {a }}$ bulha hiperfonética, esta mais intensa na área tricúspide. Sopros sistólicos na borda esternal esquerda eram ouvidos, um rude na parte alta e outro suave na parte baixa, ambos de discreta intensidade. O fígado não foi palpado.

O eletrocardiograma mostrou ritmo sinusal e sinais de sobrecarga de cavidades direitas. A onda $\mathrm{P}$ era apiculada, com 2,5 $\mathrm{mm}$ de amplitude em D2. A onda R tinha $14 \mathrm{~mm}$ em V1 e inexistiam potenciais de ventrículo esquerdo. SÂP: $+50^{\circ}$, SÂQRS: $+110^{\circ}$, SÂT: $0^{\circ}$.

Imagem radiográfica - Mostra aumento da área cardíaca às custas das cavidades direitas. 0 arco médio é escavado e a trama vascular pulmonar diminuída (fig. 1).

Impressão diagnóstica - Esta imagem sugere o diagnóstico de cardiopatia congênita com hipofluxo pulmonar com estenose pulmonar acentuada, ocasionando aumento da área cardíaca em decorrência da presença evolutiva da insuficiência tricúspide. A ausência da dilatação pulmonar pós-estenótica decorre da limitação exagerada do fluxo pulmonar, em face do grau mais acentuado do defeito.

Diagnóstico diferencial - São lembradas outras cardiopatias com hipofluxo pulmonar e com área cardíaca aumentada como na atresia pulmonar com septo ventricular íntegro e na anomalia de Ebstein, ambas também ocasionando a insuficiência tricúspide, e que por isso podem se exteriorizar da mesma maneira.

Confirmação diagnóstica - Os elementos clínicos sugeriram o diagnóstico da estenose pulmonar valvar acentuada dada a presença do sopro sistólico discreto, alto na borda esternal esquerda, ao

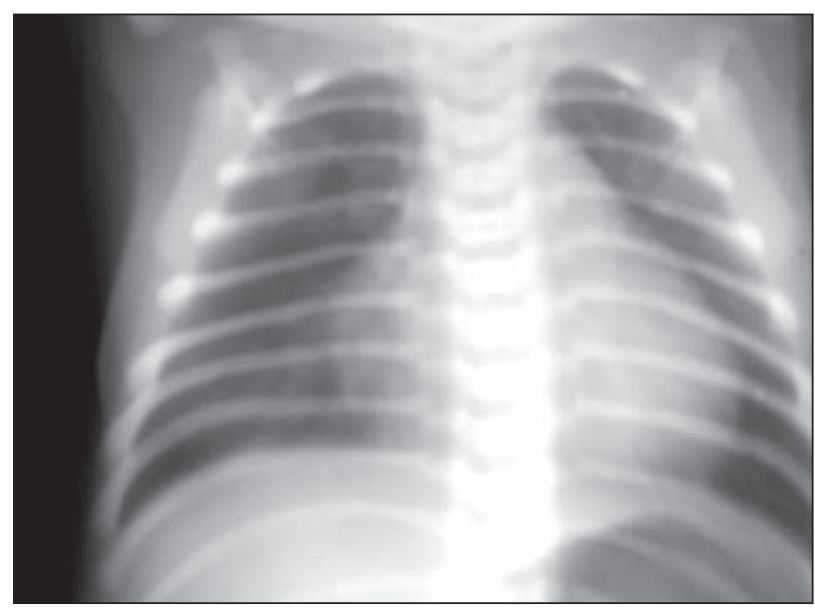

Fig. 1 - Radiografia de tórax salienta cardiomegalia às custas do aumento das cavidades direitas com trama vascular pulmonar diminuída.

lado da segunda bulha hipofonética e da trama vascular pulmonar diminuída e com sobrecarga ventricular direita no eletrocardiograma. O sopro sistólico suave, ouvido na parte mais baixa da borda esternal, decorre da conseqüente insuficiência valvar tricúspide. O ecocardiograma confirmou o diagnóstico com gradiente transvalvar pulmonar estimado em $109 \mathrm{mmHg}$. A valva pulmonar era trivalvular, espessada e pouco móvel. A insuficiência valvar tricúspide era moderada. 0 cateterismo cardíaco mostrou a estenose pulmonar valvar acentuada, a insuficiência tricúspide também acentuada e acentuada hipertrofia ventricular direita. As pressões encontradas foram: AD: 4, VD: 135/4, TP: média de $5 \mathrm{mmHg}$, AE: 4, VE: 140/4 mmHg.

Conduta - Após a valvoplastia pulmonar com cateter-balão 8x20 a pressão sistólica de ventrículo direito diminuiu para $36 \mathrm{mmHg}$ e a pressão média da artéria pulmonar para $14 \mathrm{mmHg}$, sendo que as pressões de ventrículo esquerdo eram de 90/6 mmHg. A evolução clínica foi boa com desaparecimento da cianose e diminuição dos sopros sistólicos. 